LA W RENCE LIVERMORE N A T IO N A L LABORATORY
Quantification Of Aluminum Increase Factors for Curtainwall Design Using Finite Element Methods

L. D. Leininger, S. M. Gallant

January 15, 2013

Structures Congress 2013

Pittsburgh, PA, United States

May 2, 2013 through May 4, 2013 
This document was prepared as an account of work sponsored by an agency of the United States government. Neither the United States government nor Lawrence Livermore National Security, LLC, nor any of their employees makes any warranty, expressed or implied, or assumes any legal liability or responsibility for the accuracy, completeness, or usefulness of any information, apparatus, product, or process disclosed, or represents that its use would not infringe privately owned rights. Reference herein to any specific commercial product, process, or service by trade name, trademark, manufacturer, or otherwise does not necessarily constitute or imply its endorsement, recommendation, or favoring by the United States government or Lawrence Livermore National Security, LLC. The views and opinions of authors expressed herein do not necessarily state or reflect those of the United States government or Lawrence Livermore National Security, LLC, and shall not be used for advertising or product endorsement purposes. 


\title{
QUANTIFICATION OF ALUMINUM INCREASE FACTORS \\ FOR CURTAIN WALL DESIGN USING FINITE ELEMENT METHODS
}

\author{
Lara D. Leininger, Ph.D. ${ }^{1}$, Sharon M. Gallant ${ }^{2}$, P.E. S.E.
}

1. Lawrence Livermore National Laboratory, 7000 East Ave., L-098, Livermore, CA 94550

2. Hinman Consulting Engineers, Inc., One Bush St., Suite 500, San Francisco, CA 94104

lara@llnl.gov

\begin{abstract}
In this paper we present structural analysis of an aluminum-backed curtain wall system to inform blast-resistant structural design practice. This analysis focuses on the expected material response of an aluminum curtain wall support to a set of typical blast loadings used in U.S. government criteria for domestic projects. Dynamic experiment test results of aluminum samples are used with a three-dimensional finite element hydrocode to account for over-strength, dynamic strengthening, and postfailure response of aluminum. The analysis shows that a curtain wall member under high-rate (blast) loading that is prescribed to fail using the recommended values of yield strength in the criteria documents, actually has very little evolved plastic strain. Further analysis shows that the combination of both the measured quasi-static yield over-strength and dynamic yield strength of specific aluminum evaluated exceeds the design recommendations prescribed in government design criteria in excess of $30 \%$ for the 6063 aluminum evaluated. The additional fidelity provided by the more accurate material properties improved the calculated performance of the structural member to the point that a member upgrade would not be required.
\end{abstract}

\section{Background}

This paper quantifies the difference between structural design and analysis of curtain wall systems. Structural analysis focuses on the response that is expected based on test data. In this approach, material properties from tests on experimental coupons are used in the constitutive model for aluminum. These values are readily available in such engineering references such as the Machinery's Handbook and the Mechanical Engineering Design Handbook [5, 9]. Structural design is about what is allowable based on a margin of safety and surety. This requires constitutive properties which are conservative and have very high confidence intervals (in excess of $90 \%$ ). In the absence of building code for blast design, there are technical documents from the DoD, GSA, DOS, and ASCE which are commonly referenced to meet the Standard of Care for blast design. These standards mitigate the occurrence of failures which result from design error, or materials that do not meet the expected strengths. However, there could be instances when a structural element does not meet the allowable design standard, but engineering analysis indicates that it is not expected to fail.

Previous studies have demonstrated that following the Standard of Care, Single Degree Of Freedom (SDOF) modeling with prescribed ductility and rotation limits for curtain wall design, will give a conservative solution compared to using dynamic 
Finite Element Analysis (FEA) [1]. In one study published at Structures Congress 2010 [17], the material reduction for the facade (by weight) was between 40 and 75\%, and the connection reaction reduction was between 20 and 30\% for two cases studied. This research demonstrates the value of FEA in the design of curtain wall, and that its proper implementation can lead to significant savings in building construction.

However, FEA is not feasible for the day-to-day structural engineering practice. The criteria documents from the government sponsor (usually the GSA, DoD, or DOS) prescribe charge weights, standoffs, and performance criteria based on the SDOF design practice. In this practice, there is a balance between glass pane capacity and the aluminum mullion structural support. This balance is more challenging when criteria limits and blast loading change, and new limits allow a structure to pass when it didn't previously. The practicing engineer is then faced with wondering if their prospective design is within a margin of safety. In these unique cases, FEA allows the structural engineer to evaluate the likelihood of structural failure based on the first-principles of structural response integrating specific dynamic material properties.

Using overly conservative material strength in the design of curtain wall may seem like a good idea, but it can lead to structural designs that are too expensive to construct. In a limited funding environment, this practice does not make building occupants safer from blast because it reduces the number of structures that may, consequently, be hardened. In this paper we use FEA to examine aluminum material properties to establish a less conservative methodology for designing curtain wall facades. FEA coupled with experimental data reveals a new range of increase factors which could be used in SDOF to prevent overly-conservative curtain wall designs that still meet the requirements set forth by the government agency and ASCE design guidance.

\section{A Perspective on the Minimum Construction Requirements for Curtain Wall}

Guidance for the design of façade systems for structures exposed to blast risk is governed by the "Authority Having Jurisdiction" per ASCE's "Blast Protection of Buildings” ASCE/SEI 59-11 [2]. This guide is a comprehensive compilation of best practices in design for mitigation and contains guidelines for Exterior Envelope, including Curtain Wall Systems (\$8.3.3). Prior to the publication of 59-11 there were criteria documents published by the individual government agencies, most notably the GSA and DoD (including the US Army Corps of Engineers, USACE).

In both the GSA and DoD guides, the Yield Strength, $\sigma_{y}$, of a material can have Strength Increase Factors (SIF) and Dynamic Increase Factors (DIF) applied to them per the following equation: $\sigma_{\mathrm{y}}=\sigma_{\mathrm{y}}{ }^{*} \mathrm{a} * \mathrm{c}$, where $\mathrm{a}=\mathrm{SIF}$ and $\mathrm{c}=\mathrm{DIF}$. The USACE prescribes these increase factors for aluminum in PDC TR 06-01 [6] and are shown in Table 1. 
Table 1: Comparison of Typical Aluminum Strengths and Increase Factors from PDC TR 06-01, Table 6-2 [6]

\begin{tabular}{|l|c|c|c|}
\hline Type of Aluminum & Yield Strength [MPa] & $\begin{array}{c}\text { Strength Increase } \\
\text { Factor (SIF) }\end{array}$ & $\begin{array}{c}\text { Dynamic Increase } \\
\text { Factor (DIF) }\end{array}$ \\
\hline $6061-\mathrm{T} 6$ & $241(35 \mathrm{ksi})$ & 1.07 & 1.02 \\
\hline $6063-\mathrm{T5}$ & $110(16 \mathrm{ksi})$ & 1.16 & 1.02 \\
\hline $6063-\mathrm{T} 6$ & $172(25 \mathrm{ksi})$ & 1.12 & 1.02 \\
\hline
\end{tabular}

The Unified Facilities Criteria, or UFCs, do not specifically recognize aluminum in UFC 3-340-02 [15] or UFC 3-340-01 [13], however correspondence with DoD Explosive Safety Board Policy Development Division specifies that engineers should use the criteria for cold-formed steel. Per UFC 3-340-02 §5-34.2, the SIF and DIF for cold-formed steel at $\sigma_{\mathrm{y}}=33 \mathrm{ksi}$ is 1.21 and 1.1 (regardless of strain rate) respectively. UFC 4-010-01 (including Change 2007) does not give SIF and DIF guidance.

\section{Aluminum Material Properties}

As previously mentioned, there are a number of sources for aluminum material data. For design purposes, we look first to the Aluminum Design Manual, ADM, [1]. The ADM provides the density, Poisson ratio, tensile yield strength $\left(\sigma_{y}\right)$, and tensile ultimate strength $\left(\sigma_{\mathrm{UT}}\right)$. Per the ADM, $\sigma_{\mathrm{y}}$ and $\sigma_{\mathrm{UT}}$ properties are the minimum values, and they are established only after "sufficient" test data has been accumulated to "adequately determine the form of the frequency distribution curve and to provide a reliable estimate of the population mean and standard deviation". According to the manual, most properties conform to a normal distribution and are derived from a minimum of 100 tests from at least 10 different lots of material. The strength values provided in the ADM provide a 95\% confidence level for $99 \%$ of the material. These are the good properties to use for standard structural engineering practice and they correspond with the values prescribed by the USACE in Table 1.

For example, in the ADM the allowable material properties for the aluminum alloy 6063-T6, which is commonly used as a structural element in window mullions, is shown as: $\sigma_{\mathrm{y}}=25 \mathrm{ksi}, \sigma_{\mathrm{UT}}=30 \mathrm{ksi}, \mathrm{E}=10,100 \mathrm{ksi} v=0.33$, and $\rho=0.097 \mathrm{lb} / \mathrm{in}^{3}$. From the MIDAS database [11] we find a typical value of tangent modulus: $\mathrm{E}_{\mathrm{T}}=95.3 \mathrm{ksi}$. Using Strength of Materials theory and assuming a yield offset of $0.002(0.2 \%)$, the Equivalent Plastic Strain (EPS) at failure for this material is calculated to be 0.057 (5.7\%).

However, from standard handbooks the values for the yield strengths of aluminum 6063-T6 alloy were generally higher, on the order of 30-31 ksi [5, 9]. These expected yield strength values were also reinforced by an extensive series of testing of 6063-T5 aluminum performed at a range of strain rates [20]. In Ref. 20, the yield strength is measured to be 30.1-30.3 ksi (in the expected strain rates of interest) and the corresponding fracture strains are 0.0945-0.1149 (9.4-11.5\%). These higher yield strengths support an increase in the SIF for the values shown in Table 1 to 1.2-1.24, and the higher fracture strains suggest that DIF increases are appropriate. 
At Lawrence Livermore National Laboratory, there is an extensive web-based central repository for activities related to experimental testing and materials modeling: Material Implementation, Database, and Analysis Source (MIDAS) [11]. MIDAS includes both databases and software utilities for storing, viewing, managing, implementing, and deploying material properties including experimental data, material models, and their parameters. Using MIDAS, we are able to look at and compare the strength (or flow stress) for a number of aluminum material samples that have been dynamically tested at a range of strain rates. The material models and parameters include the Mie-Gruniesen equation of state, Steinberg-Guinan shear modulus model, and a number of common flow stress models including PrestonTonks-Wallace, the Mechanical Threshold Model, Steinberg-Lund, SteinbergGuinan, and Johnson-Cook. This data, and its associated material model parameters, is more valid for blast design analysis because it includes testing in the loading regimes for which the blast response occurs. However, unlike the data found in the ADM, this data does not have documented confidence intervals and - in some cases it may be based on a small set of dynamic data.

Figure 1 shows a representative aluminum plotted from the MIDAS browser. The abscissa is strain and the ordinate is stress. The red solid lines are two common constitutive models for aluminum at 300K: Steinberg-Guinan [10] and Johnson-Cook [4]. The green open circles are experimental data for a range of strain-rates $[3,18$, 19]. The lower strength curves are for a strain rate of $1 \mathrm{e}-9 \mu \mathrm{s}^{-1}\left(0.001 \mathrm{~s}^{-1}\right)$ and the highest strength curve is for $0.0048 \mu \mathrm{s}^{-1}\left(4800 \mathrm{~s}^{-1}\right)$. By mean of comparison, UFC 3$340-02$ gives a range of strain rates for compression members of $0.02-0.05 \mathrm{~s}^{-1}\left(\sim 10^{-8}\right.$ $\left.\mu \mathrm{s}^{-1}\right)$. These curves support the importance of constitutive models that capture the strain-rate dependence of aluminum when analyzing curtain wall, and these curves support higher DIFs than those shown in Table 1.

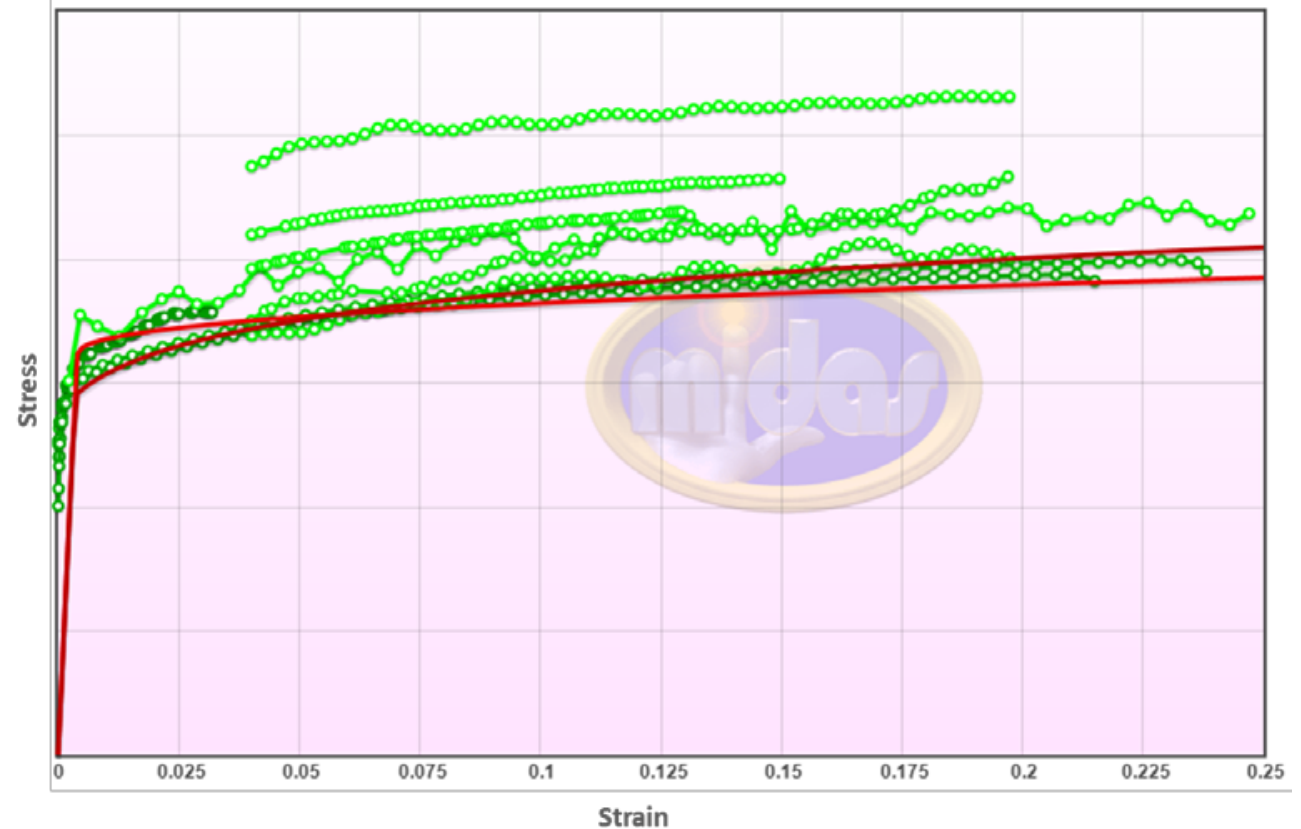

Figure 1: Experimental Data and Constitutive Models for Aluminum plotted with MIDAS 


\section{Design and Analysis Study}

In order to quantitatively compare the design and analysis methodologies, we performed a study that considers an aluminum-backed curtain wall system. The system geometry is based notionally on the building shown in Figure 2. It consists of a 10"x3"x3/8" aluminum mullion extruded from 6063-T6 aluminum. The typical glass pane has a 9.75' tributary width, a 25.5' span, and is assumed to have fix-pin end conditions based on typical configuration. The window pane is a lay-up of heat strengthened glass with PVB and air inner layers, with properties given out of WINGARD PE 5.5.1. The yield strength is specified in Table 1 as $25 \mathrm{ksi}$ with SIFs and DIFs of 1.12 and 1.02 respectively. The two loading cases, denoted as "Low Load" and "High Load", are based on typical loadings prescribed in domestic government guidance.

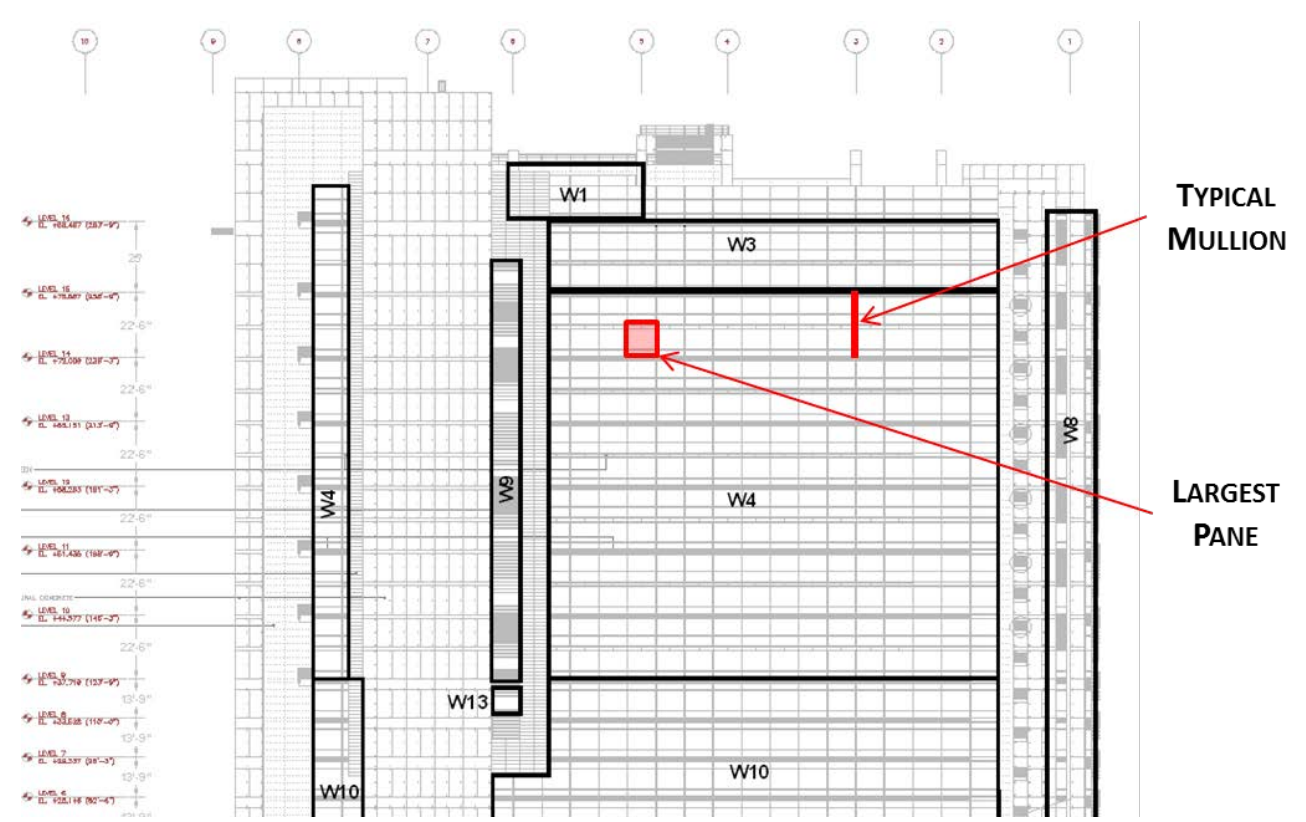

Figure 2: Architectural Elevation showing general window system studied for this paper

\section{SDOF Analysis}

Blast Analysis Modules (BAM) has been used to perform analysis of the façade framing members. BAM is a set of proprietary codes written on the MatLab platform and based on information in the military technical manual TM5-1300 [13].

Analytical methodologies employed by BAM include: approximate, analytical, discrete, and experimentally derived results. Input and result information are presented using a numeric and graphical interface that include the input values, responses, blast load parameters, static and dynamic properties, among others.

Structural calculations using the USACE PDC performance criteria for low level of protection [7] are shown in Figure 3. These results are derived from first principles of structural dynamics using non-linear generalized stiffness methods to predict response of structural components. Material behavior is modeled using idealized elastic, perfectly-plastic stress-deformation functions, based on actual structural support conditions and material properties. The model properties selected provide the 
same peak displacement and fundamental period as the actual structural system in flexure. Response to shear is evaluated by comparing the demand on the element to its capacity. Maximum deflection is evaluated by solving the governing differential equations for the lumped mass system using numerical methods.

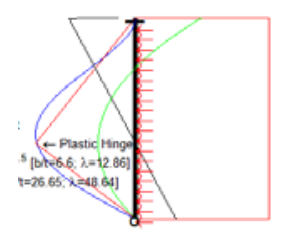

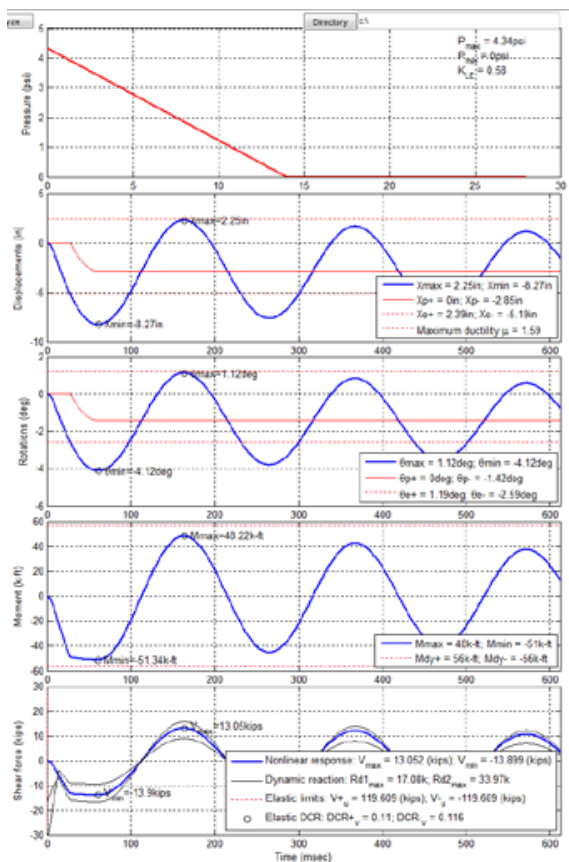

(a)

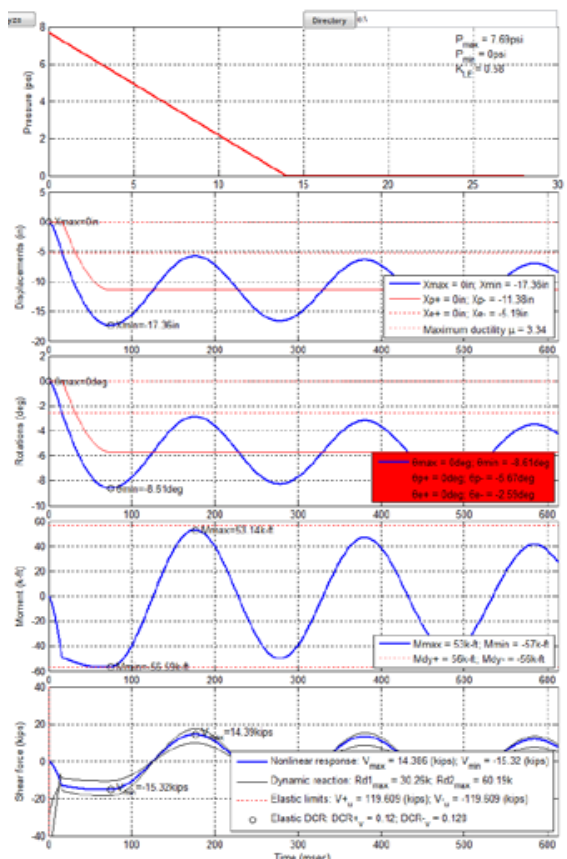

(b)

Figure 3: BAM results for the (a) Low Load and (b) High Load

The BAM results show that the mullion:

- Passes under the Low Load and criteria (6 $6^{0}$ support angle rotation criteria, ductility ratio of 7, and Shear Demand Capacity Ratio, DCR, less than 1) with $\theta, \mu$, and DCR of $4.12^{0}, 1.59$, and 0.11 respectively.

- Fails under the High Load and criteria (6 $6^{0}$ support angle rotation criteria, ductility ratio of 7, and Shear Demand Capacity Ratio, DCR, less than 1) with $\theta, \mu$, and DCR of $8.61^{0}, 3.34$, and 0.13 respectively.

\section{Finite Element Analysis}

The finite element model is shown in Figure 4. It is built-up of 8-node hexahedral solid elements and 4-node shell elements. The aluminum solid elements have both a bi-linear Elastic, Perfectly-Plastic (EPP) material model (using the same properties as the SDOF model) and the Johnson-Cook (JC) constitutive and damage model. The glass is built with elastic shell elements (also using the same properties as the SDOF model).

The boundary conditions are also shown in Figure 4. The span is given a fix-pin end condition, which is the same as the SDOF analysis, and based on the construction of the typical high-rise shown in Figure 2. There is no pin on the window frame so the window is free to follow the motion of the mullion oscillation, just as in the SDOF. Since an as-built window system will have a pin connection in the no-window-failure 
balanced loading condition, the displacements shown in this analysis are expected to be lower than expected, but within 13\% (based on a sensitivity study of the parameter). The pin condition fixes $\mathrm{x}, \mathrm{y}, \mathrm{z}$ displacements and the fix constrains $\mathrm{x}, \mathrm{y}, \mathrm{z}$ displacement and $\mathrm{x}, \mathrm{y}, \mathrm{z}$ rotation. By fixing the $\mathrm{z}$-direction displacement we are engaging full catenary action. This is a conservative assumption which will give us higher values of equivalent plastic strain (with smaller displacements relative to the SDOF). There is a symmetry condition running down the edges of the window pane.

Since this study uses a constitutive model that shows stress triaxiality and subsequent material dynamic damage, a convergence study was performed. In this model we look at three increasing levels of convergence ranging from a coarse model with 1 element per cm (2.54 elements per inch), a medium model at 2 elements per $\mathrm{cm}$, and a fine model with 3 elements per $\mathrm{cm}$. These models are comprised of $54 \mathrm{k}, 284 \mathrm{k}$, and 746k elements respectively, and run for $33 \mathrm{~min}$ on 8 processors, 61 minutes on 48 processors, and 59 minutes on 112 processors respectively. The results of the study indicate that the medium model (2 elements per $\mathrm{cm}$ ) is converged. The loading condition is based on the Low Load.

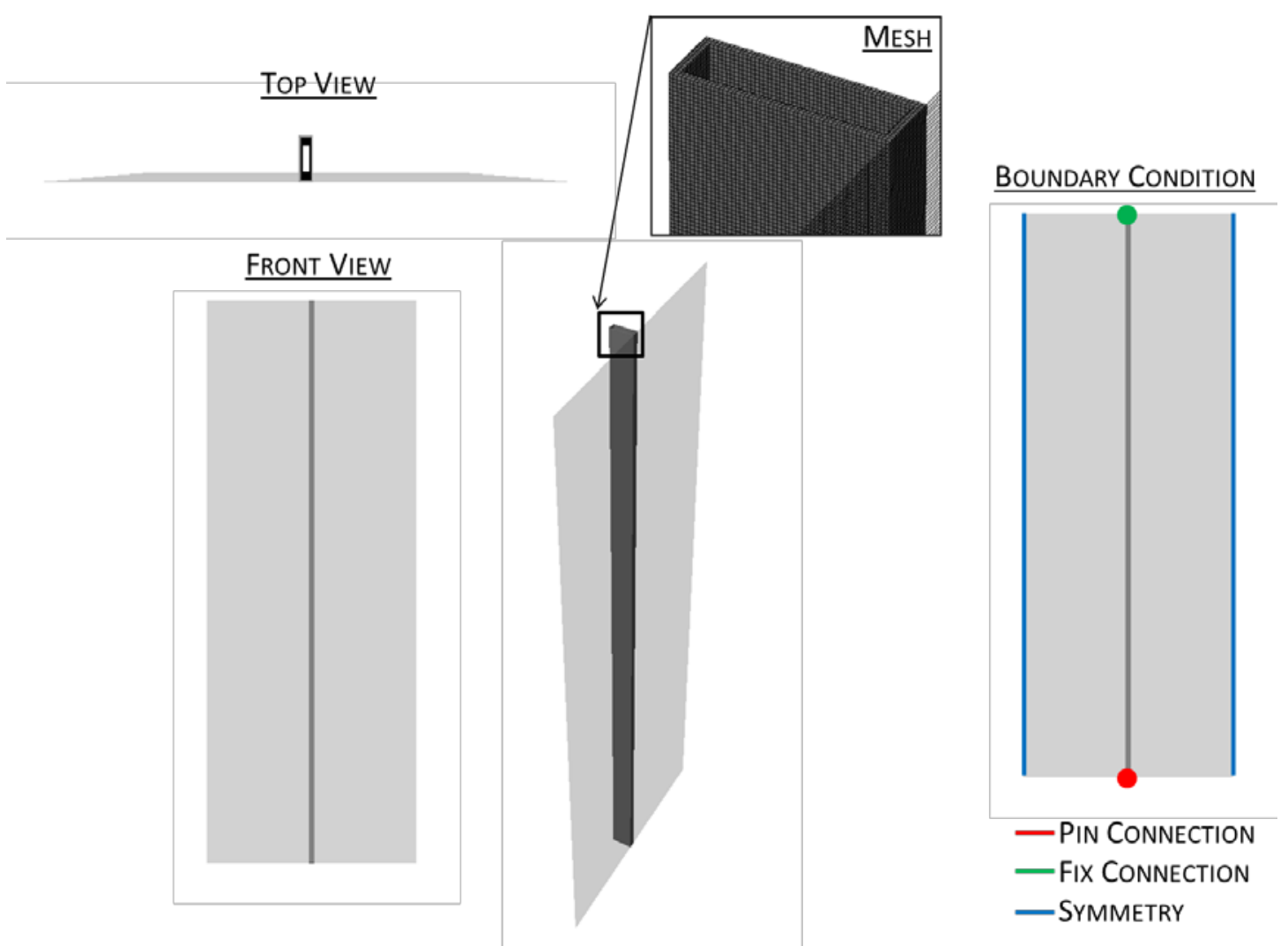

Figure 4: Finite Element Model of the aluminum mullion

Results of the FEA using both the Low and High Loads are presented in Table 2, Figure 5, and Figure 6. These results indicate the peak displacement of the mullion almost doubles with the higher loading for both the EPP and JC material models. The SDOF/BAM analysis also showed a doubling of displacement, which resulted in 
support rotations that exceed the criteria limits for the High Load. The FEA shows that the peak equivalent plastic strain in the mullion is still far below the failure strain of the aluminum (EPS is on the order of 1\%, or less, compared to the expected failure limit of $5.7 \%$ for quasi-static loading and up to $11.5 \%$ for dynamic loading).

Comparison of the strains for the EPP model and JC model show a decrease in EPS (and displacement) because of the dynamic strength hardening (and increased performance) accounted for in the JC model. The plasticity evolved in all cases is small relative to the failure limits for this aluminum, indicating that the mullions are not expected to fail under either loading.

The displacements in the SDOF are higher than the displacements in the FEA. This is because the SDOF analysis assumes no catenary (unrestrained end condition) and the FEA assumes full catenary (fixed, or restrained, end condition). The reality of the situation is that the as-built curtain wall system is somewhere between unrestrained and restrained case, especially since the systems are balanced up to the failure of the glass pane. By means of comparison, when the FEA is run with no catenary, the displacements match the SDOF within $4 \%$.

Table 2: FEA results of Low Load and High Load analysis for the material models used in the study

\begin{tabular}{|c|c|c|c|c|}
\hline & $\begin{array}{c}\text { Peak Stress } \\
{[\mathrm{ksi}]}\end{array}$ & $\begin{array}{c}\text { Peak } \\
\text { Displacement } \\
{[\mathrm{in}]}\end{array}$ & $\begin{array}{c}\text { Equivalent } \\
\text { Plastic Strain } \\
{[\%]}\end{array}$ & $\begin{array}{c}\text { Peak Strain } \\
\text { Rate } \\
{\left[\mathrm{s}^{-1}\right]}\end{array}$ \\
\hline Elastic, Perfectly-Plastic & & & & \\
\hline Low Load & 28.6 & 4.19 & 0.4 & \\
\hline High Load & 28.6 & 7.99 & 1.1 & \\
\hline Johnson-Cook & & & & 4.3 \\
\hline Low Load & 31.4 & 4.08 & 0.3 & 75.7 \\
\hline High Load & 31.9 & 7.95 & 0.4 & \\
\hline
\end{tabular}
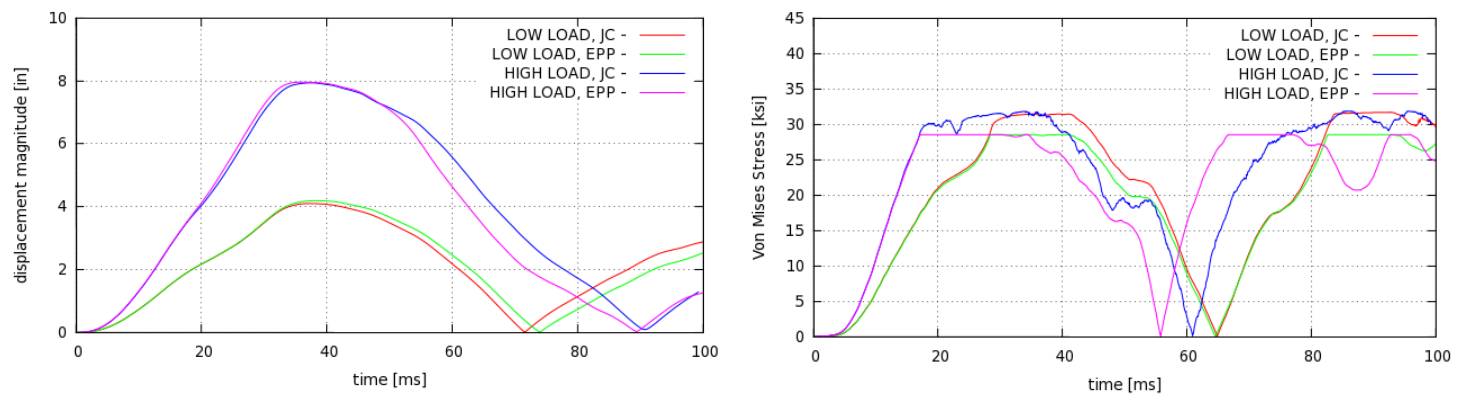

Figure 5: Comparison of Low Load and High Load Displacement and Stress Time histories for the material models used in the study 


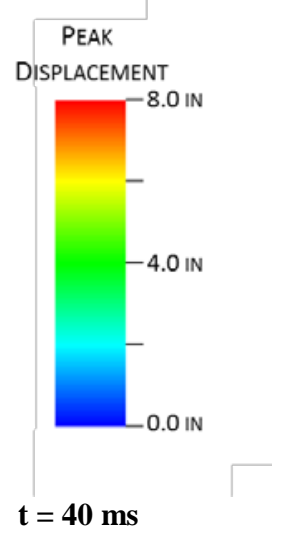

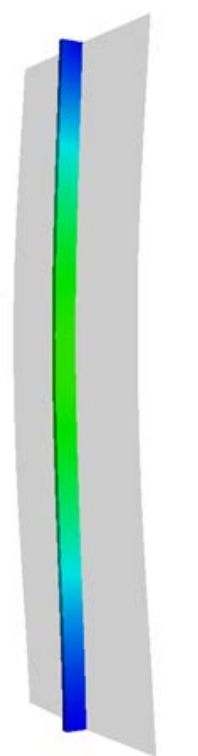

(a) Low Load Elastic, Perfectly-Plastic

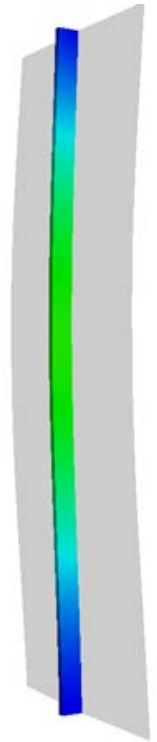

(c) Low Load Johnson-Cook

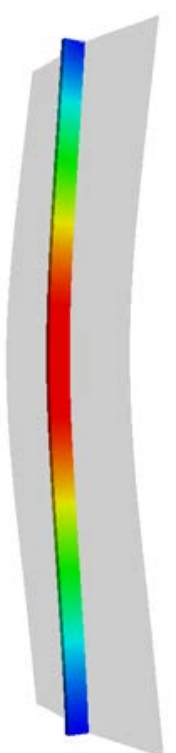

(b) High Load

Elastic, Perfectly-Plastic

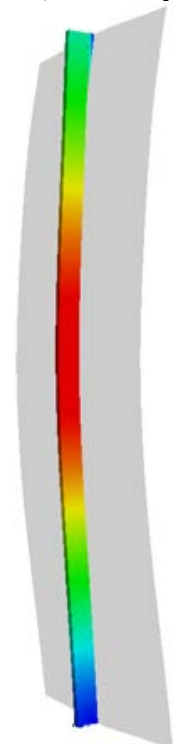

(d) High Load Johnson-Cook

Figure 6: Peak displacement fringe plot comparing the response of a Low Loaded mullion (a) \& (c) and a High Loaded mullion (b) \& (d) using and Elastic, Perfectly-Plastic (EPP) model and the Johnson-Cook (JC) material properties

The strain rates shown in the analysis were higher than typical blast design strain rates (prescribed in UFC 3-340-02). The high end of the experimental data is $0.33 \mathrm{~s}^{-1}$ and strain rates in the FEA are up to $75.7 \mathrm{~s}^{-1}$. Using the experimental data, fitting a logarithmic curve, and extrapolating the data to the strain rates shown in Table 2, we see an increase in yield strength to $32.1 \mathrm{ksi}$ for the Low Load case and $33.1 \mathrm{ksi}$ for the High Load case. These extrapolations are shown in Figure 7(a) and the yield strengths calculated are consistent with the peak stresses shown in Table 2. Since both of these models use the same constitutive relationship, this increase is solely attributed to the dynamics of the material response. 
We also noted that there is a potential outlier in the experimental data. At a strain rate of $0.24 \mathrm{~s}^{-1}$, the measured yield strength drops from 31.1 to 30.4 then back to $31.3 \mathrm{ksi}$. A drop of over $2 \%$ in strength with increasing strain rate is unexpected and nonphysical. If we remove this outlier in our extrapolation, then the dynamic yield strength increases to $32.4 \mathrm{ksi}$ for the Low Load case and $33.6 \mathrm{ksi}$ for the High Load case as shown in Figure 7(b).

Given the previous discussion in the Aluminum Material Properties section, a SIF of 1.2 is appropriate, so the expected yield strength of 6063-T6 aluminum goes to $30 \mathrm{ksi}$. This analysis further supports dynamic yield strength increases (from the proposed 30 $\mathrm{ksi}$ ) in the range of $2.4 \mathrm{ksi}$ to $3.6 \mathrm{ksi}$, or DIFs of 1.08 to 1.12 . Again, this data is based on available testing of 6063-T5 aluminum. T5 is a slightly weaker alloy than 6063-T6 and is significantly weaker than other widely used alloys like 6061-T6. Although we believe that all aluminums will have similar increase factors, each alloy should be evaluated individually.

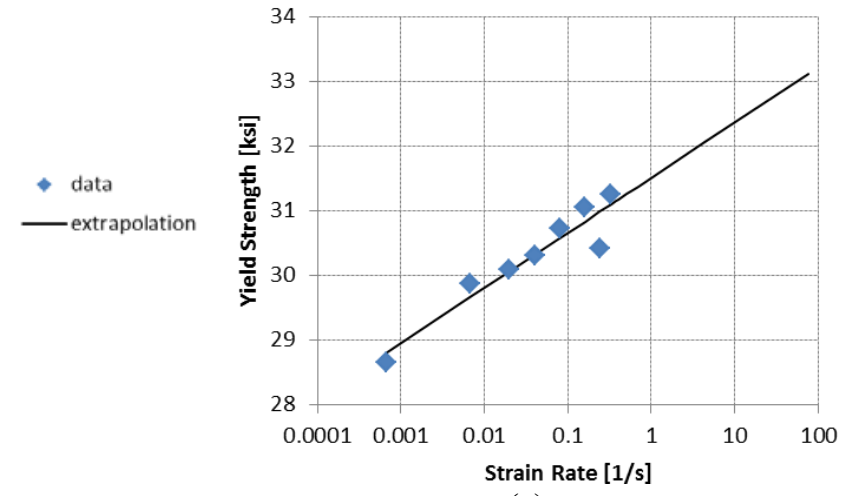

(a)

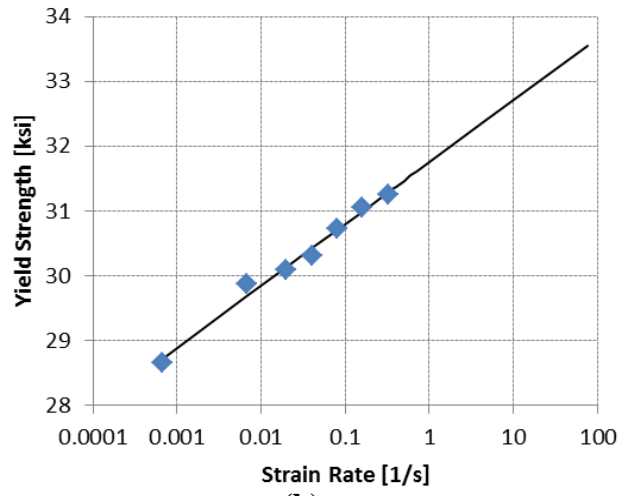

(b)

Figure 7: Increase in yield strength as a function of strain rate for 6063-T5 aluminum when all the data is used for a logarithmic fit (a) and when one of the outliers is removed (b)

Based on the literature and the analysis presented here, we recommend raising the Strength increase Factors (SIFs) for 6063 aluminum to1.2, and the Dynamic Increase Factors (DIFs) from 1.08 to 1.12 for a yield strength of up to $34 \%$ higher than the prescribed design strength. These numbers are expected to result in improvements to SDOF calculated performance, which will reduce overly-conservative design.

\section{Summary}

In this paper we have evaluated the design of a blast-resistant curtain wall system (representative of what is seen in domestic projects), and performed a material study of the aluminum member. This study allowed us to quantify the expected response and compare to the design criteria. We performed Single Degree of Freedom (SDOF) analysis using two loading combinations which showed the transition to failure for the mullion. Finite Element Analysis (FEA) of the same design, loading, and material properties, shows that the yield strength is exceeded, but there is little plasticity for the same two cases, and that both mullions should pass. Further FEA using the expected values of the 6063 aluminum material based on experimental data (and including dynamic increase effects), shows even more mullion performance 
improvement with less displacement and less plastic strain. This further justifies an increase in dynamic yield strength and supports the conclusion that this test mullion would not fail. The use of more pragmatic material properties saved time and money by not inducing a redesign.

\section{Acknowledgments}

LLNL-CONF-610492: This work was performed under the auspices of the U.S.

Department of Energy by Lawrence Livermore National Laboratory under Contract

DE-AC52-07NA27344.

\section{References}

1. Aluminum Design Manual: Specifications \& Guidelines for Aluminum Structures, The Aluminum Association, Arlington, VA, June 2005.

2. ASCE/SEI 59-11, Blast Protection of Buildings, American Society of Civil Engineers (2011).

3. Gray, G.T. and S. R. Chen, 2003, Los Alamos National Laboratory (Export Controlled).

4. Johnson, G.R. and T.J. Holmquist, Test Data and Computational Strength and Fracture Model Constants for 23 Materials Subjected to Large Strains, High Strain Rates, and High Temperatures, Los Alamos National Laboratory LA11463-MS, January 1989.

5. Machinery's Handbook $25^{\text {th }}$ Edition, Industrial Press: New York, New York, 1996.

6. PDC-TR 06-08. Single Degree of Freedom Structural Response Limits for Antiterrorism Design. USACE PDC Technical Report. 20 October 2006.

7. PDC-TR 10-02. Blast Resistance Design Methodology for Window Systems Designed Statically and Dynamically. USACE PDC Technical Report. 19 April 2012

8. Salim, H., Dinan R., Kiger, S., and Townsend, P.T., "Blast-Retrofit Wall Systems Using Cold -Formed Steel Studs," Proceedings of the 16th ASCE Engineering Mechanics Conference, July 16-18. Seattle, Washington, 2003.

9. Shigley, Joseph and Charles Mischke. Mechanical Engineering Design Handbook, $5^{\text {th }}$ Edition, McGraw-Hill: San Francisco, California, 1989.

10. Steinberg, Daniel. J., "Equation of State and Strength Properties of Selected Material", Lawrence Livermore National Laboratory, UCRL-MA-106439, February 1996.

11. Tang, Meijie, A Comprehensive Resource For Modeling, Simulation, and Experiments, Research Highlights article, LLNL Science \& Technology Review, Jan/Feb 2012:

12. https://str.llnl.gov/JanFeb12/tang.html

13. TM 5-1300, NAVFAC P-397, AFR 88-22. Structures to Resist the Effects of Accidental Explosions. November 1990.

14. UFC 3-340-01, TM 5-855-1, AFPAM 32-1147(I), NAVFAC P-1080, DAHSCWEMAN-97 Design and Analysis of Hardened Structures to Conventional Weapon Effects (FOUO). 01 June 2002.

15. UFC 3-340-02. Structures to Resist the Effects of Accidental Explosions. 5 December 2008. 
16. UFC 4-020-01, DoD Security Engineering Facilities Planning Manual, 11 September 2008.

17. Van Eepoel, Peggy and Scott Wood, "Inelastic Dynamic Finite-Element Design of Light Gauge Metal Stud Façade Systems for Blast Loading," Proceedings of ASCE/SEI Structures Congress, May 13-15, Orlando, Florida, 2010.

18. Vecchio K.S. and Gray, G.T., Metall Trans. 26A (1995) 2545.

19. Yadav, S. et al., Acta Mettall. Mater. 43 (1995) 4453-4464.

20. Zhu, H. et al. Characterization and Simulation of Mechanical Behavior of 6063 Aluminum Alloy Thin-walled Tubes, Advanced Materials Research, vols. 197-198 (2011) pp 1500-1508. 